\title{
Subclavian Artery Pseudoaneurysm following Stab Injury and Its Surgical Approach: A Case Report and Literature Review
}

\author{
Md. Abir Tazim Chowdhury*, Sohail Ahmed, Md. Zulfiqur Haider, S. M. A. Zulker Nine, \\ Md. Kamrul Hasan, Mohammad Sanaul Hoque Sarker
}

Department of Cardiothoracic and Vascular Surgery, Evercare Hospital, Dhaka, Bangladesh

Email: *chowdhuryabir0@gmail.com

How to cite this paper: Chowdhury, Md.A.T., Ahmed, S., Haider, Md.Z., Nine, S.M.A.Z., Hasan, Md.K. and Sarker, M.S.H. (2021) Subclavian Artery Pseudoaneurysm following Stab Injury and Its Surgical Approach: A Case Report and Literature Review. World Journal of Cardiovascular Surgery, 11, 61-67.

https://doi.org/10.4236/wjcs.2021.117009

Received: June 23, 2021

Accepted: July 27, 2021

Published: July 30, 2021

Copyright $\odot 2021$ by author(s) and Scientific Research Publishing Inc. This work is licensed under the Creative Commons Attribution International License (CC BY 4.0).

http://creativecommons.org/licenses/by/4.0/

\begin{abstract}
Penetrating injuries to the subclavian arteries as well as post traumatic pseudoaneurysm involving Subclavian artery (SCA) are very much uncommon. We present one case of a 21 year-old male sustained a physical assault with a post stab injury left subclavian artery pseudoaneurysm. He was referred to our facility, two days after sustaining a penetrating chest trauma over left infraclavicular area of the chest. The presentation, diagnostic procedures and surgical approach for management of this very rare injury are discussed.
\end{abstract}

\section{Keywords}

Penetrating Chest Injury, Subclavian Artery (SCA) Injury, Pseudo Aneurysm of Subclavian Artery, Diagnosis, Surgical Approach

\section{Introduction}

Post-traumatic pseudoaneurysm is very rare entity and pseudoaneurysm of subclavian artery (SCA) is the rarest one because trauma to it is rare [1] [2]. Most common site of pseudoaneurysm is common femoral artery, followed by radial and brachial artery [2]. However, penetrating SCA injuries are fairly uncommon and constitute less than $2 \%$ of all civilian vascular traumas and most surgeons do not see more than a few such injuries in their career [3] [4] [5] [6]. Complications associated with such pseudoaneurysm are estimated around $2 \%-6 \%$ [2]. Limited clinical experience, complex local anatomy combined with the difficult surgical exposure of proximal injuries makes these injuries challenging even for experienced surgeons. The operative fatality rate ranges from $5 \%$ to $30 \%$ and is attributed to rapid exsanguination and a high incidence of concomitant injuries 
[5] [6]. We present a case of the patient in whom pseudoaneurysm of left subclavian artery developed after 2 days of stab injury and was successfully treated by surgical excision of pseudoaneurysm and removal of clotted blood with direct closure of injured left SCA.

\section{Case Summary}

A previously healthy 21-years-old male patient diagnosed as a case of post stab injury left subclavian artery pseudoaneurysm following physical assault 2 days back, was referred to emergency department of Evercare Hospital Dhaka, Bangladesh, after getting initial resuscitation (with 6 unit whole blood transfusion) and evaluation in two different hospitals. On arrival patient was found conscious, oriented, GCS was E4V5M6, Blood Pressure 110/70 mmHg Pulse 68/min, Oxygen Saturation 92\%, Heart S1 + S2 + 0, Lungs-bilaterally vascicular breath sound over the lung fields and there was found tight bandage over left infraclavicular area packed with multiple gauze. Left upper limb found swollen with normal temperature and oxygen saturation, but there was absence of brachial, radial and ulnar pulsations. Upper limb CT angiography verified presence of a bilobed pseudoaneurysm from mid third of left Subclavian artery with maximum anterior and posterior length of pseudoaneurysm $40 \mathrm{~mm}$ and $30 \mathrm{~mm}$ respectively, along with open cut injury in left upper chest wall invading muscles and contains hemorrhage and small air pockets (Figure 1). After short preoperative preparation, the patient underwent surgical intervention under general anesthesia. Initially, a left sided clavicular incision starting at the sternoclavicular junction, extending over the medial half of the clavicle and then curving downward over the left deltopectoral groove, then after careful dissection left sternoclavicular joint was disarticulated and the clavicle was retracted upwards to take vascular control of left distal SCA and proximal axillary artery. But further proximal SCA access was difficult due to packed gauzes with clotted blood at the penetrating site and those packed gauzes also pushed vessels downward and laterally and distorted typical anatomy. Then for more proximal exposure a additional of a mini-median sternotomy upto $4^{\text {th }}$ intercostals space with left lateral extension done with joining to the standard clavicular incision (Figure 2). Thus, access and loop the proximal subclavian artery was done. Intravenous heparin (5000 IU) was administered. Proximal subclavian artery and axillary artery both clamped. Packed gauze with 4 - 5 fist of clotted blood was removed. Dissection and separation of pseudoaneurysm followed by excision was done with cautery (Figure 3).

A transected injury noted at middle $1 / 3^{\text {rd }}$ of subclavian artery. After ensuring surgical toileting transected SCA was repaired end to end with polypropylene suture 6-0 directly without any tension. There was also found a partial tear of vein at the junction of left suclavian and axillary vein, which was also repaired with polypropylene suture. After achieving hemostasis and putting two 14 numbers negative suction romovac drain in supraclavicular and axillary region, a 24 number chest drain tube at pericardial cavity, left clavicle fixed with sternum 


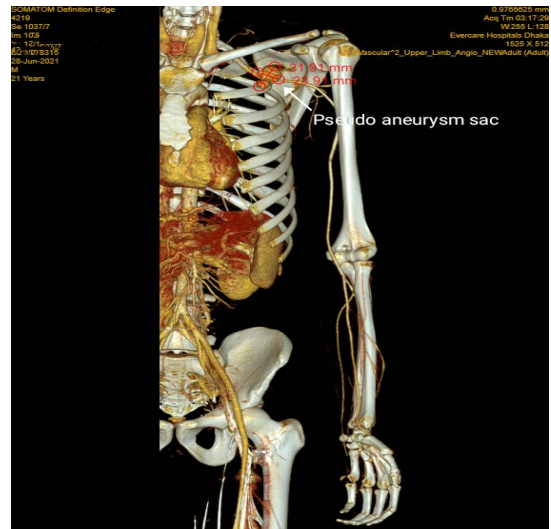

(a)

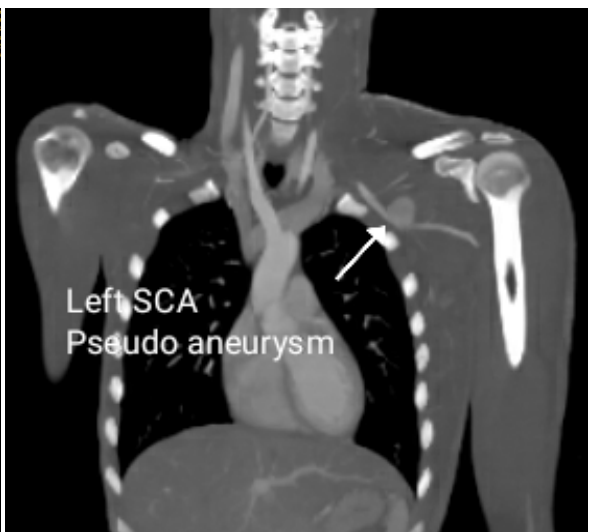

(b)

Figure 1. Preoperative contrast computed tomography (CT) revealed bilobed pseudoaneurysm sac (aprox. $32 \mathrm{~mm} \times 24 \mathrm{~mm}$ in diameter) from mid third of left Subclavian artery; (a) three-dimensional view (b) coroal view.

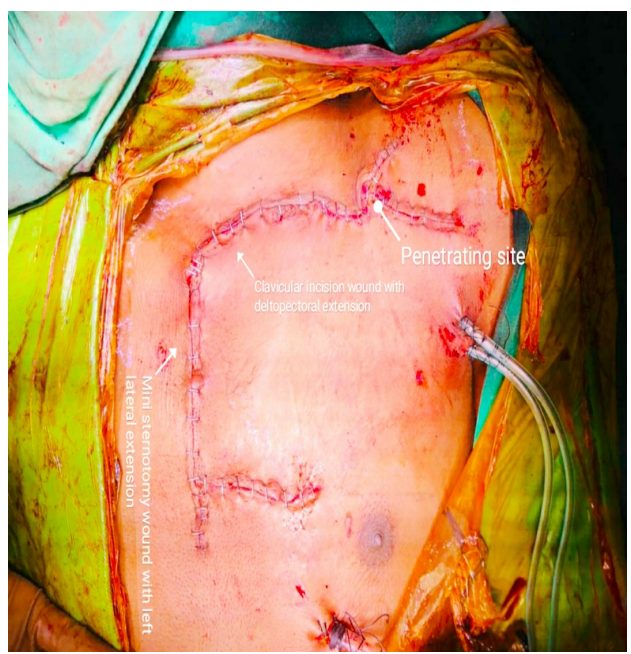

Figure 2. Surgical wound after closure.

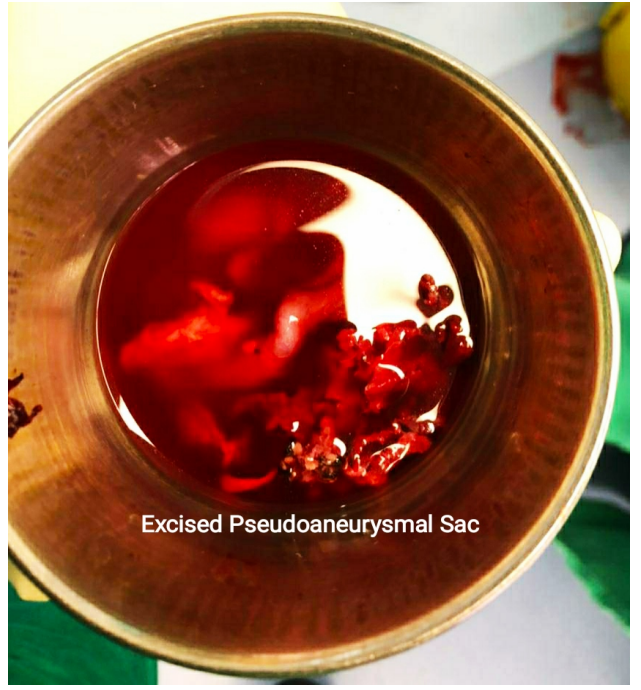

Figure 3. Excised pseudoaneurysmal sac. 
and sternal wound closed with sternal wires and skin closed with stapler wound closed in layer and skin closed with stapler (Figure 2). Radial and ulnar artery pulsation checked and found both palpable audible with hand held Doppler. Patient was shifted to Cardiothoracic postoperative, ICU for hemodynamic monitoring with broad spectrum antibiotic coverage and systemic heparinization. His postoperative laboratory parameters were normal and recovery period was uneventful except left upper limb edema which was resolved with limb elevation. Pericardial drain and romovac drains removed on $2^{\text {nd }}$ and $4^{\text {th }}$ postoperative day (POD) respectively and on the $5^{\text {th }}$ POD the patient was discharged to home. Figure 4 showing Chest X-ray on $4^{\text {th }}$ POD prior removal of romovac drains, revealed no collection. On $14^{\text {th }}$ POD in his first follow-up visit skin staplers were removed, wound found healthy and all the arterial pulse of left upper limb were palpable and there was no sign of neurological impairment.

\section{Discussion}

Post-traumatic pseudoaneurysm is uncommon. The most frequent cause for such pseudoaneurysm is iatrogenic and among the arteries which are mostly involved are common femoral, radial and brachial arteries [7]. Penetrating injuries involving SCA are particularly devastating because it carries a high incidence of concomitant injuries contributes to significant morbidity. Mortality prior to reach hospital is about $75 \%$ and mainly attributed long-term morbidity is due to brachial plexus injuries [8] [9]. Studies showed that amount of blood transfusions and mortality rate of Subclavian venous injuries (isolated and/or associated) was significantly higher [10]. In our case patient also had a venous injury at left subclavian and axillary vein junction and transfused 6 unit of blood prior surgery. Possible explanation is that, the property of veins is inability to constrict so venous injuries are less likely to stop bleeding spontaneously [10]. However, delayed presentation isn't uncommon because hard vascular signs and a pulse deficit are only seen in about $20 \%$ of patients; extensive collateral circulation within

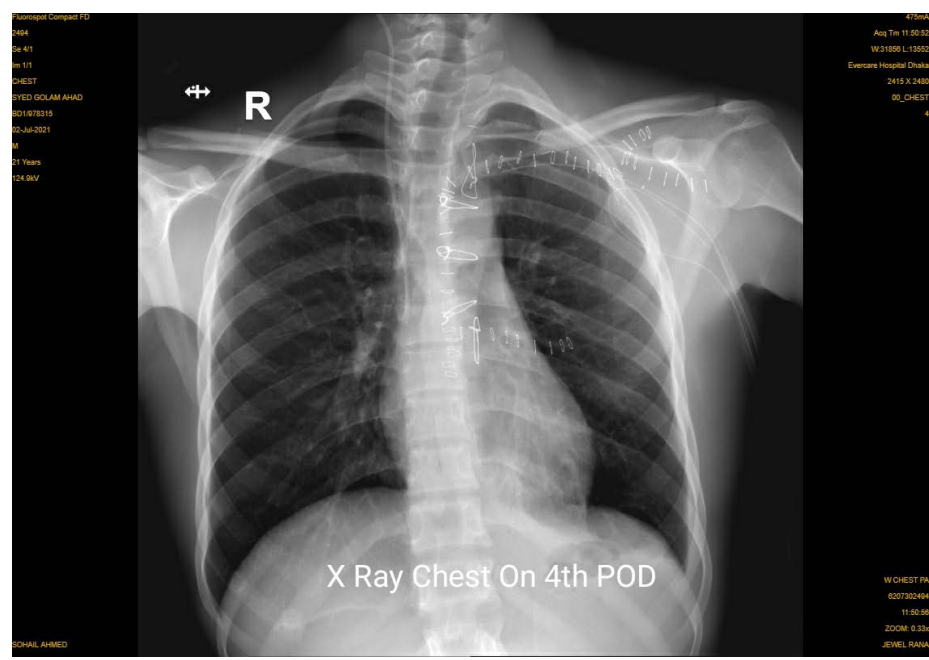

Figure 4. Post operative chest $\mathrm{x}$-ray on $4^{\text {th }}$ POD. 
the upper limb prevents ischaemia even within the presence of proximal injuries [9] [11]. Angiogram is extremely helpful to determine the site of injury, screening for occult and associated vascular injuries, whether patients get benefit from endovascular intervention or not and most importantly for planning the surgical approach [11]. In current case we use CT angiogram to reveal the status of injury and affected limb circulation. Regarding management of penetrating SCA aneurysm, some recent studies showed use of SCA stent to close the opening between SCA and pseudoaneurysm not superior than surgical correction because there may remain high risk of infection in already formed pseudoaneurysm sac. Excision of that pseudoaneurysm is mandatory [12] [13]. In this reported case, the patient was not approached with endovascular management, as the patient was flown from a remote city of Bangladesh, where limited resources for endovascular management, and in our institute, we don't routinely practice endovascular procedures for vascular injuries. As the entry wound was also tightly packed and there may presence of uncertainty of injuries our surgical team was decided to do open techniques for the surgical correction without delaying time. Surgical correction of a SCA pseudoaneurysm connecting with a normal SCA can be done with simple excision of pseudoaneurysmal sac without sacrificing the part of SCA either direct or vein patch closure of that opening with polypropylene suture. In some cases rarely excision of part of Subclavian artery may require with replacement by autogenous veins or prosthetic grafts to establishment for limb circulation [7] However, early preoperative pressure control of bleeding and surgical exposure of the subclavian and proximal axillary vascular injuries may challenge even the most experienced surgeon because major portions of these vessels are retroclavicular in position [10]. Although various types of surgical approaches have been described in different literature for the management of penetrating SCA injuries [9] [10] [14] but an adequate incision is most essential to take vascular control, identify the site of injured vessels and other associated injury and for correcting those injuries. Traditionally, for right subclavian artery injuries it has been taught that surgical approach should be with a midline sternotomy with a clavicular incision. However, recommendation for left-sided injuries is an anterolateral thoracotomy or "trap door" incision [10]. In our case, we used the combination of mini sternotomy upto 4 ICS and a left sided clavicular incision extending from sternoclavicular junction to left deltopectoral groove was used with disarticulation SCJ provides an excellent exposure to take adequate vascular control and to deal with injuries. With this approach we found minimal risk of per-operative bleeding as we take all proximal and distal vascular control and pseudoaneurysmal sac can remove totally and repair of vascular injury also easier. In this reported case we found transected SCA at its mid part without any long segment involvement, so repaired directly using polypropylene suture. In a study conducted on 50 surgically managed penetrating SCA injuries revealed, reported primary repair of the SCA was possible in more than half of their patients and among interposition grafting patients, $70 \%$ of patients were injured with gunshot wounds and $35 \%$ of stab wound and they reserved ligation 
for cases with delayed presentation, sepsis, critically ill and haemodynamically unstable patients needing damage control surgery [11]. There were no major postoperative complications in current case except postoperative limb oedema, which was transient and resolved with limb elevation. However literature revealed, a trap door incision is associated with excessive bleeding, severe postoperative pain, and respiratory complications [10]. There were no associated or residual brachial plexus injuries in current case. Regarding brachial plexus injuries studies mentioned earlier, were encountered in $12 \%$ of cases and neurological deficit remains the leading cause of morbidity of those case and they stated that the neurological deficit on presentation of some cases were results from compression of the nerves by a haematoma or an aneurysm and resolves after expedient surgical intervention [11].

Pre-operative resuscitation and vascular imaging with angiography was important to make decision regarding surgical approach. Adequate surgical exposure to gain vascular control along with reconstruction to re-establish limb perfusion contributed to the successful outcome of current case.

\section{Conclusion}

The excision of pseudo aneurysm is the simple and safe surgery for any surgeon with having proper anatomical knowledge. Surgical planning is an important issue in any form of a traumatic vascular injury and using a preoperative angiography will guide to plan the surgical approach. An adequate proximal and distal control of vessels is must for the safe excising of a pseudoaneurysm of SCA. By proper anatomical dissection pseudo aneurysm can be excised without damaging the surrounding vital structures and thus vascular injuries can be repaired meticulously. Finally, timely managements are more important things to prevent complications like infection, rupture, gangrene and also establishing the perfusion contributed to the successful outcome of patient.

\section{Conflicts of Interest}

The authors declare no conflicts of interest regarding the publication of this paper.

\section{References}

[1] Sherev, D.A., Shaw, R.E. and Brent, B.N. (2005) Angiographic Predictors of Femoral Access Site Complications: Implication for Planned Percutaneous Coronary Intervention. Catheterization and Cardiovascular Interventions, 65, 196-202. https://doi.org/10.1002/ccd.20354

[2] Muller, D.W., Shamir, K.J., Ellis, S.G. and Topol, E.J. (1992) Peripheral Vascular Complications after Conventional and Complex Percutaneous Coronary Interventional Procedures. The American Journal of Cardiology, 69, 63-68. https://doi.org/10.1016/0002-9149(92)90677-Q

[3] Wall, M.J., Granchi, T., Liscum, K. and Mattox, K.L. (1996) Penetrating Thoracic Vascular Injuries. Surgical Clinics of North America, 76, 749-761. https://doi.org/10.1016/S0039-6109(05)70478-3 
[4] Demetriades, D., Rabinowitz, B., Pezikis, A., Franklin, J. and Palexas, G. (1987) Subclavian Vascular Injuries. British Journal of Surgery, 74, 1001-1003. https://doi.org/10.1002/bjs.1800741114

[5] Fletcher, J.P. and Little, J.M. (1988) Injuries of Branches of the Aortic Arch. Australian and New Zealand Journal of Surgery, 58, 217-219. https://doi.org/10.1111/j.1445-2197.1988.tb01042.x

[6] Pate, J.W., Cole Jr, F.H., Walker, W.A. and Fabian, T.C. (1993) Penetrating Injuries of the Aortic arch and Its Branches. The Annals of Thoracic Surgery, 55, 586-592. https://doi.org/10.1016/0003-4975(93)90255-G

[7] Nagre, S.W. (2016) Subclavian Artery Pseudoaneurysm Secondary to Accidental Stone Chip Injury and Its Excision. Journal of Cardiovascular Medicine and Cardiology, 3, 30-31. https://doi.org/10.17352/2455-2976.000027

[8] McKinley, A.G., Carrim, A.A. and Robbs, J.V. (2000) Management of Proximal Axillary and Subclavian Artery Injuries. British Journal of Surgery, 87, 79-85. https://doi.org/10.1046/j.1365-2168.2000.01303.x

[9] Aksoy, M., Tunca, F., Yanar, H., Guloglu, R., Ertekin, C. and Kurtoglu, M. (2005) Traumatic Injuries to the Subclavian and Axillary Arteries: A 13-Year Review. Surgery Today, 35, 561-565. https://doi.org/10.1007/s00595-005-2990-y

[10] Demetriades, D., Chahwan, S., Gomez, H., Peng, R., Velmahos, G., Murray, J. and Bongard, F. (1999) Penetrating Injuries to the Subclavian and Axillary Vessels. Journal of the American College of Surgeons, 188, 290-295.

https://doi.org/10.1016/S1072-7515(98)00289-0

[11] Sobnach, S., Nicol, A.J., Nathire, H., Edu, S., Kahn, D. and Navsaria, P.H. (2010) An Analysis of 50 Surgically Managed Penetrating Subclavian Artery Injuries. European Journal of Vascular and Endovascular Surgery, 39, 155-159. https://doi.org/10.1016/j.ejvs.2009.10.013

[12] Koreny, M., Riedmüller, E., Nikfardjam, M., Siostrzonek, P. and Müllner, M. (2004) Arterial Puncture Closing Devices Compared with Standard Manual Compression after Cardiac Catheterization: Systematic Review and Meta-Analysis. Jama, 291, 350 357. https://doi.org/10.1001/jama.291.3.350

[13] Carey, D., Martin, J.R., Moore, C.A., Valentine, M.C. and Nygaard, T.W. (2001) Complications of Femoral Artery Closure Devices. Catheterization and Cardiovascular Interventions, 52, 3-7. https://doi.org/10.1002/1522-726X(200101)52:1<3::AID-CCD1002>3.0.CO;2-G

[14] Lin, P.H., Koffron, A.J., Guske, P.J., Lujan, H.J., Heilizer, T.J., Yario, R.F. and Tatooles, C.J. (2003) Penetrating Injuries of the Subclavian Artery. The American Journal of Surgery, 185, 580-584. https://doi.org/10.1016/S0002-9610(03)00070-9 